\title{
BUILDING A GIS DATABASE FOR A TYPICAL URBAN SETTING $v(A$ CASE STUDY OF THE F.U.T. YOLA MAIN CAMPUS)
}

\author{
A. A. MUSA \\ (Received 28 August, 2009; Revision Accepted 2 November 2007)
}

\begin{abstract}
An attempt is being made in this paper to build a GIS database for the Federal University of Technology Yola, using the ArcView GIS package. The spatial data itself was achieved by using conventional field survey methods. It was then later transferred into the computer via a scanner.

The attribute data, which were collated from various departments, were entered into the computer in tabular form and linked with the spatial data.

The outcome of the database was quite impressive. It has not only increased the speed of retrieving data but has allowed a unique kind of flexibility, which was practicably impossible in the past.

\section{INTRODUCTION}

Geographic Information System (GIS) is a computer-based technology that has witnessed tremendous growth and popularity within the last decade. The Environmental System Research Institute - ESRI (1990) defines the GIS thus:

An organized collection of computer hardware, software, geographic data and personnel designed to efficiently capture, store, update, manipulate, analyze and display all forms of geographically referenced information.

Database building involves capture and storage of both spatial and attributes data into the computer. As Ndukwe (1997) rightly pointed out, the GIS does not hold maps or pictures, rather it holds a database. This is the main difference between a GIS and a computer mapping system, which is meant for production of graphic output only. Database systems provide the means of storing a wide range of geographic information and updating it without the need to re-write the programs as new data sets are entered (ESRI, 1990).

The lack of a GIS database for the Federal University of Technology Yola (FUTY) campus has

made access to information about the FUTY environment considerably slow and inefficient. It has also made decision making regarding the location of physical developments in FUTY very difficult, faulty and inaccurate. Most of the infrastructures and utilities are designed and maintained based entirely on the 'on the spot' assessment of the field technicians and artisans employed by the University. The consequence of this is not far fetched. While some electric transformers explode frequently due to overload, other transformers are under utilized. While water pipes in some parts of the campus frequently burst due to too much pressure of water, other parts of the campus don't even get water at all.

The very few geographic information on FUTY available are in the form of paper maps located in the shelves of different departments. Apart from the fact that the maps are in different scales, making it difficult to perform overlay operations, the durability of the maps is questionable. Very often they get torn and dirty due to frequent use. Alternatively, rodents and termites could eat them up. A comprehensive GIS database for FUTY will most certainly address the problems above.

The importance of a robust GIS database as a sin-qua-non to the efficient solution of
\end{abstract}

A. A. Musa, Department of Surveying \& Geo-informatics, Federal University of Technology Yola 
environmentally related problems is no longer in dispute. Juhl (1994) reported how the city of Canberra (Australia) used the GIS to reduce costs and increase productivity. The managers of the GIS have been able to minimize staff and save a lot in terms of cost. Also the GIS had enabled other agencies to avoid duplicating effort, data and resources and to meet their objective economically and easily. Memmi (1995) also reported how the GIS helped in exploring diamonds (kimberlites and lamproites) in North Central United States. The GIS database includes geological, geophysical and remote-sensing information relevant to diamond exploration. In yet another report Anderson (1992) described how the GIS was instrumental to the efficient refuse disposal system in the city of Portland (North West Oregon. U.S.A.). It provided the investigators with a powerful tool for posing "what-if " questions, and also enabled block maps with associated customer value to be created.

Building an exhaustive GIS database for FUTY is a very Herculean task, and is therefore not intended. Rather a more moderate database will be attempted with the aim to:

(i) Demonstrate the procedure for database creation in a GIS.

(ii) Compare the efficiency of the GIS with the present data storage system.

(iii) Provide a baseline framework of geographic data upon which other data could be incorporated at a later date.

\section{METHODOLOGY:}

Spatial information was obtained through ground survey methods, while the attribute information was obtained from the office files of the appropriate supervising departments. The map created from ground surveys was scanned into the computer and used as background for creating various layers of spatial data. Seven layers were created - i.e. layers for buildings, streets, power lines, pipelines, boreholes, transformers and finally generators. For six of these layers, an attribute table was attached for each. In the case of the building layer, five attribute tables were linked to each other and attached to the layer.

\section{MATERIALS:}

Steel tapes
Nikon NE-20S digital theodolite
Ranging poles
GARMIN'S Global Positioning System
(GPS) 12 Personal Navigator

Personal Computer, equipped with a Hewlett Packard ScanJet 5300c scanner and ESRI's ArcView GIS.

\section{DATA COLLECTION:}

The kind of data required could be grouped into two types - the spatial data and the attribute data. The spatial data include the spatial distribution of the various houses, road networks, water pipelines, bore-holes, power-lines etc within the campus. The attribute data on the other hand consists of specific attributes of each object, relevant to the efficient management of the campus. For instance, the attributes of each residential building would include number of bedrooms, name of occupier, rank and department of occupier.

\section{SPATIAL DATA}

To get the spatial data in place, a survey of the built up areas of the campus was carried out. The field survey commenced by establishing survey stations all over the campus. These survey stations were then accurately coordinated. Coordination was done by occupying each station and finding the coordinate of the station using the global Positioning System (GPS). From the coordinated survey stations, angles and distances were then taken to points of detail using a combination of theodolite and steel tapes. The survey stations thus became the control points from which surrounding details were located. To fix the pipelines in place an artisan from the Works \& Maintenance Dept joined the survey team, and gave a general description of how the pipes were laid. Data acquired from the field were then used in plotting a detail map of the area surveyed.

\section{ATTRIBUTE DATA:}

Majority of the attribute data were collated from the files of the relevant departments. For instance details of the residential houses were obtained from 'Works and Maintenance Unit' while details of the occupiers were obtained from the 'Housing \& Staff Development Unit'. Likewise details of the hostels were collected from the porters of each hostel.

The vast majority of other utilities do not have their attributes documented. For instance, to obtain information about the generators, field visits to the generator houses had to be made, and every bit of information read off the generating sets, likewise with the transformers. In the case of 
pipelines and power-lines, verbal information from the more experienced artisans was documented.

\section{DATABASE CREATION:}

\section{SPATIAL DATABASE}

The detail map of FUTY earlier mentioned was scanned into the computer. The scanned map was exported into ArcView in Tagged Image File Format (TIFF). Once in ArcView, the scanned map became the background upon which various spatial data were built. Shapefiles were created for each theme by choosing an appropriate drawing tool. The building theme was created by using the Polygon drawing tool, the streets, powerlines and water pipe line themes were created using the line drawing tool, while the bore holes, transformers and generating sets themes were put in place using the Point drawing tool.

\section{ATTRIBUTE DATABASE:}

Each time a new theme is created the theme's attribute table is also created automatically and remains in edit mode. Before adding any record to the table however, the table was broken down into various fields. The name of each field closely describes the type of data in the field. For each spatial data created, an additional record is added automatically to the theme's attribute table. The records were then updated accordingly. This way six theme tables were created. A theme table is a table that is directly linked to the theme's spatial data. Usually a unique identifier is made which links each spatial data to its record in the attribute data. The seven theme tables consisted of tables for the buildings theme, boreholes theme, transformers theme, water pipelines theme, generators theme, power-lines theme and road network theme.

For the buildings theme, five additional tables were created. These were the residential house table; the hostel table, the academic house table; the administrative house table and the others table. The residential house table were 'joined' to the building table using the JOIN tool. This is because of the one-to-one relationship existing between each residential house and its corresponding record in the attribute table. On the other hand the academic, administrative, hostels, and others tables were linked to the 'buildings' table using the LINK tool. This is because of the many-to-one relationship that existed between the spatial data and the corresponding records in the attribute table.

\section{RESULTS:}

Since the database had not been officially implemented in the university, it is difficult to ascertain the likely problems that might arise during implementation. However, preliminary test running had proved most impressive.

With this database, it is possible to compare themes without overcrowding the computer screen with too much information. For instance, the BUILDING theme could be compared with the ROAD theme (Fig 1). Alternatively the ROAD theme could be disabled while making the POWER LINE theme active, thus facilitating a comparison between buildings and electric power lines (Fig 2). This is unlike the present system in use where for each theme there is a separate map sheet, and each map sheet doesn't necessarily have to be in the same scale with the other sheets.

The 'IDENTIFY' tool in the GIS allows the attribute data for any spatial data to be displayed on the screen, immediately the spatial data is clicked with the mouse (Fig 3). In the present traditional system in use, labels are usually made near the spatial data in question, and because of space limitation, there is usually a limit to the information provided by such labels.

With the use of the 'FIND' tool, the house of any individual could be located by merely typing the individual's name. The GIS finds the house by bringing it to the center of the screen and changing its color, so that it appears different from the rest.

The database could also be queried and results of queries displayed on the screen. Thus, if residential houses of only non-academic staff of the university are selected, then only residential houses of non-academic staff will be displayed.

\section{CONCLUSION:}

This paper has tried to show that the process of converting from the traditional database system to a Geographic Information System (GIS) does not require the hi-tech knowledge and equipment common in science fiction movies. Rather what is required is the political will and commitment.

Attempts were also made at comparing the data retrieval sub-system of the GIS with that of the traditional data storage systems, which many public bodies find very reluctant to discard. Overwhelming evidence points to the fact that the traditional system is far too cumbersome, energy sapping and slow for the present jet age.

The need for more public bodies, especially municipal governments and utility companies, to embrace the GIS is therefore hereby re-echoed. 


\section{SPATIAL DATABASE FOR F.U.T.YOLA, MAIN CAMPUS}

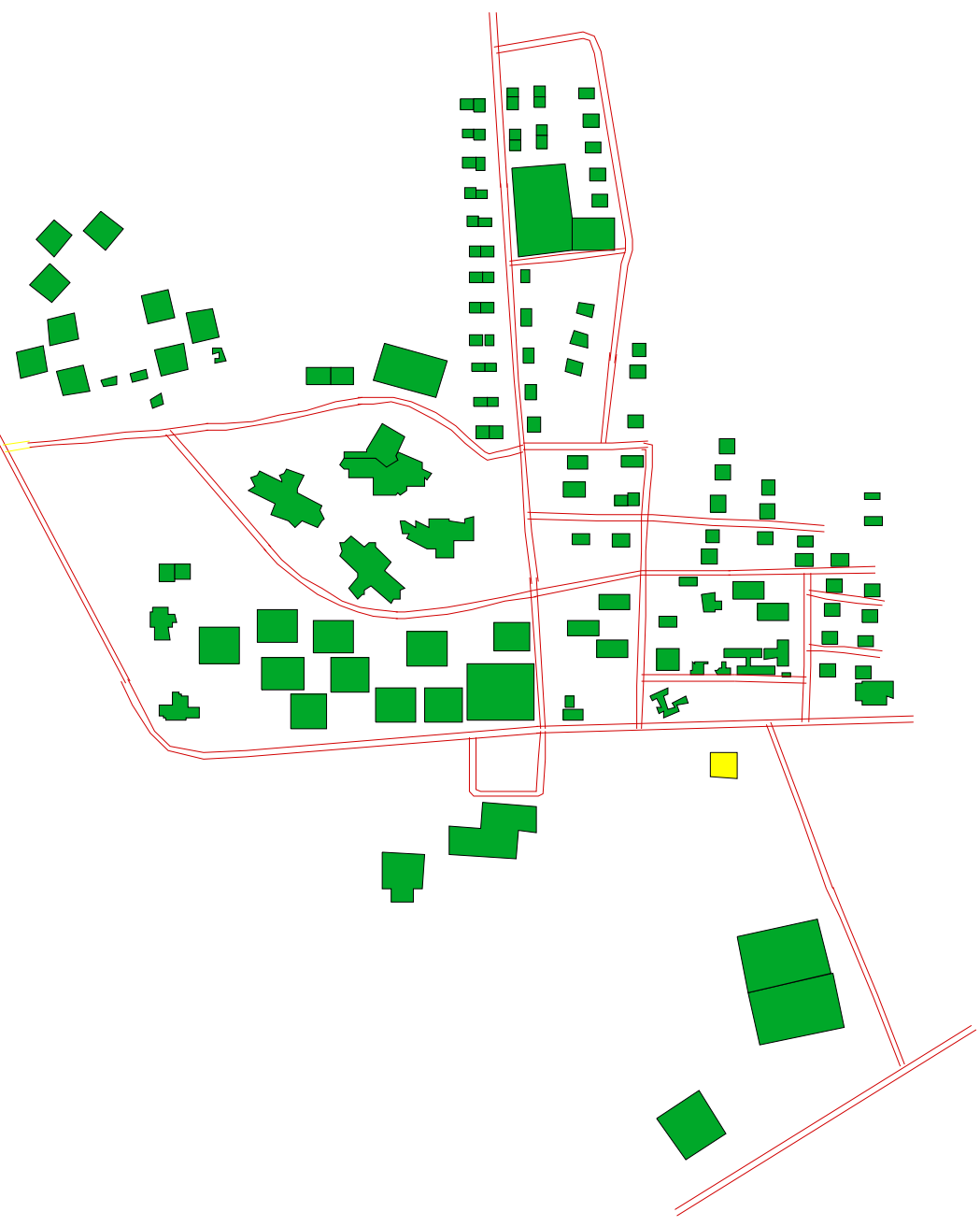

Fig 1: Spatial database depicting only buildings and road networks

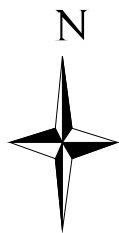


SPATIAL DATABASE OF FUT YOLA

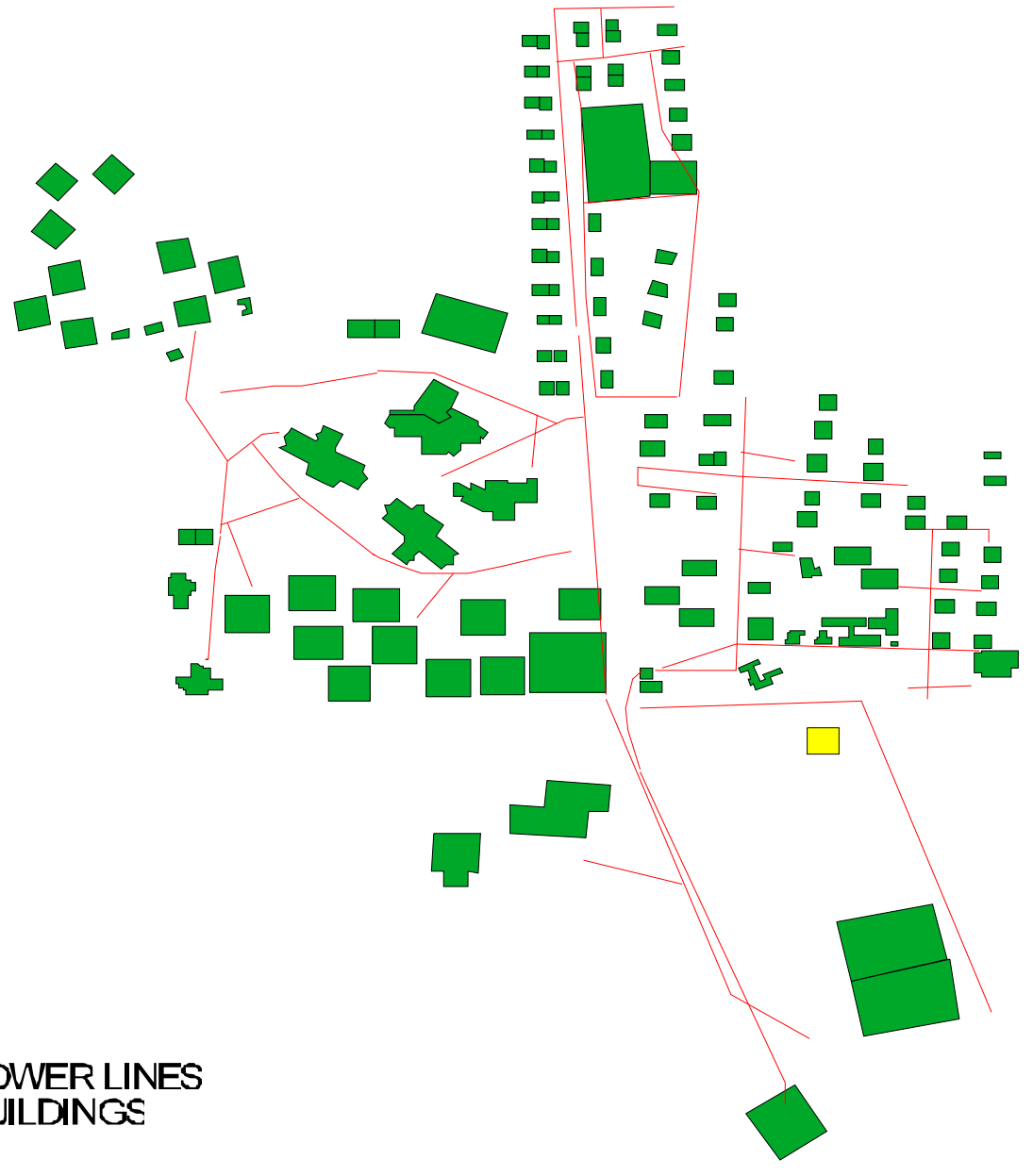

Fig 2: Spatial Database depicting houses and electric power lines.

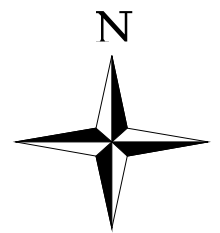




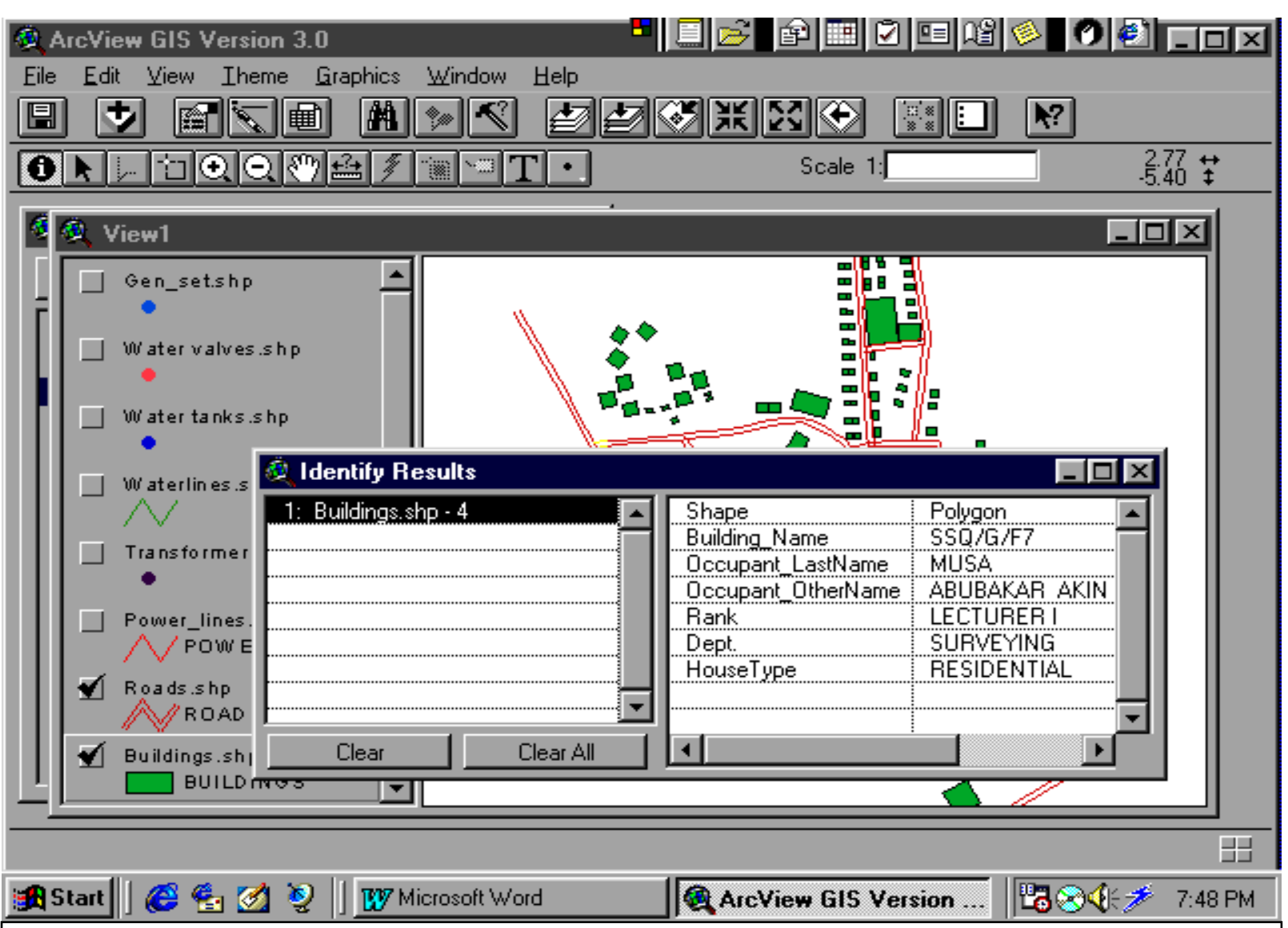

Fig 3: Using the IDENTIFY tool to determine the attribute data of a particular building .

\section{REFERENCES}

Anderson. D,, 1992. GIS Supports Garbage Hauler Franchising. GIS World 5. (5): Longman Group.

ESRI, 1996. Introduction to ArcView GIS. An ArcView User's manual by Environmental Systems Research Institute (ESRI) Redlands CA, USA.

ESRI, 1990. Understanding GIS - The Arc/Info Method. A Workbook on Geographical Information System by
Environmental Systems Research Institute (ESRI) Redlands CA, USA

Juhl. G. M., 1994. City Relies on GIS to Reduce Costs, Increase Productivity GIS World 7 (5): GIS World Inc Longman Group.

Memmi. J. M., 1995. Expertise and GIS converge for diamond Exploration GIS World Inc 8 (2): Longman Group

Ndukwe, K. Ndukwe, 1997. Principles of Environmental Remote Sensing \& Photo Interpretation. New Concept Publishers Enugu Nigeria. 

